\title{
Effect of glutathione on antimicrobial activity of levofloxacin
}

\author{
AmalA.AbdEl-Aziz ${ }^{1}$, WafaaA.Zahran², HodaMahrous ${ }^{3 *}, H_{a n y K a l i l}{ }^{1}$,Amira H.El- \\ Khayat $^{2}$,SaadiyaA. El-Nahas ${ }^{1}$
}

\author{
${ }^{1}$ Molecular Biology Department, Genetic Engineering and Biotechnology Research Institute \\ (GEBRI), University of Sadat City, Egypt \\ ${ }^{2}$ Microbiology and Immunology Department, faculty of Medicine, Menofiya University \\ ${ }^{3}$ Industerial Biotechnology Department, Genetic Engineering and Biotechnology Research Institute \\ (GEBRI), University of Sadat City, Egypt
}

Corresponding author: HodaMahrous email:hmahrous7@yahoo.com

\begin{abstract}
Overuse of antibiotics has become the major factor for the emergence anddissemination of multi-drug resistant strains of several groups of microorganisms andthis lead to search for agents that may be asolution,Fluoroquinolones are a group of antibiotics widelyused because of their broad spectrum activity against both Gram-positive and Gram-negative bacteria.

In this study We report the effect of glutathione on the antibacterial action of levofloxacin on E-coli and $S$. aureus aslevofloxacin is an important and commonly used members of the fluoroquinolonesantibiotics.Itinhibit DNA topoisomerase II and DNA topoisomerase IV activities, eventually leading tobacterial cell death. In addition, an increase of reactive oxygen species in the bacterial cells in response to levofloxacin has been shown.
\end{abstract}

Keywords: Fluoroquinolones, side effects, microbial activity and antioxidants

\section{INTRODUCTION}

Antibiotics are weapons of choice in fightagainst infectious bacterial diseases.Fluoroquinolonesare anti-microbial agents, withbroad spectrum bactericidal activity against both Gram- positive, Gramnegative bacteria, anaerobic bacteria, and even Mycobacterium(Shenoy, et al., 2011) .

The mechanism ofantibacterial action of quinolones is not completely understood;however, it has been proposed that the initial event isthe inhibition of DNA synthesis by interference with thenick sealing activity of DNA topoisomerase II (DNA gyrase)and DNA topoisomerase IV. In the presence of these antibiotics, the enzyme is trapped on the DNA, resulting in theformation of quinolone-enzyme-DNA complexes, and thesubsequent release of DNA ends from this complex leads tothe generation of "cellular poison" which ultimately leads tocell death(Kumar et al.,2011).

They haveusefulpharmacokinetic properties, achieve high tissue and serum levels, and have chemical and biological stability.Severalfluoroquinolones have been developed, andmany derivates have been synthesized to improve bactericidaland metabolic properties (Alba et al., 2008). Fluoroquinolones are well tolerated in patients but their useshave been associated with some adverse effects, includinggastrointestinal discomfort, cutaneous reactions e.g.phototoxicity, juvenile joint toxicity and adverse centralnervous system effects.Although the incidenceof these side effects is relatively low, the high prescriptionrates of these antibiotics may pose 
serious health effects on thegeneralpopulation(Naeem et al., 2016).

Fluoroquinolones, including levofloxacin,have been demonstrated to stimulate the production of reactiveoxygen species (ROS) in bacterial cells. Reactiveoxygen species are reactive byproducts formed by the partialreduction of molecular oxygen. Redox cycling of various chemical substances, including fluoroquinolones, affects the reactiveoxygen species produced by cells during the oxidation process (Goswami et al., 2006).

Fluoroquinolones are known to induce the formationof singlet oxygen and superoxide anion, which are responsible for the phototoxic effect of the fluoroquinolones. A number of diversecellular processes that lead to cell death are also mediatedthrough ROS (Kohanski et al., 2010)

Antioxidant systems prevent the uncontrolledformationof free radicals, and inhibit ROS and its reaction withbiological structures.. Antioxidant molecules, for example reduced glutathione, actagainst several oxidant compounds, such as hydrogen peroxide superoxide anion, hydroxyl radical and reactive species of carbon(Manfredini et al., 2005) The small molecules as glutathione and cysteine can reduce a wide rangeof oxidized proteins, and protect against direct and indirectoxidation of lipid membranes and proteins as an adaptiveresponse to increased basal oxidative damage caused by superoxide anion(Cexiong et al., 2009). Glutathione can also be oxidized spontaneously in thepresence of ROS and thus neutralize them by its antioxidantcapacity. Furthermore, glutathione protects cells from theeffects of the free radicals generated duringmetabolism and isconsidered to be a biological marker of the levels of antioxidantactivity (Pa'ez et al., 2010)

Aim of the work:

To determinewhether the addition glutathione can modify the susceptibility of $S$. aureus and $E$-coli to levofloxacin.

\section{MATERIAL AND METHODS}

Bacterial strains: Five urine samples were collected from patients. The specimens were processed according to standard microbiological methods. Two clinical bacterial isolates were obtained and identified by conventional techniques [Koneman, 2006] Antimicrobial susceptibility test:

It was done for the two isolates ( $S$. aureus and E-coli) by disk diffusion method against levofloxacin (Oxoid). Procedures were performed and results were interpreted according to the Clinical and Laboratory Standard Institute guidelines(CLSI, 2016).

Table 1. Zone diameter interpretive charts inhibition measurements for S. aureus(CLSI, 2016)

\begin{tabular}{|l|l|l|l|l||}
\hline Antibiotic & Disc content & Resistant & Intermediate & Sensitive \\
\hline Levofloxacin & $5 \mu \mathrm{g}$ & $\leq 15$ & $16-18$ & $\geq 19$ \\
\hline
\end{tabular}

Table 2. . Zone diameter Interpretive standards for disc diffusion susceptibility testing for E. coli (CLSI, 2016)

\begin{tabular}{|l|l|l|l|l|}
\hline Antibiotic & Disc content & Resistant & Intermediate & Sensitive \\
\hline \hline Levofloxacin & $5 \mu \mathrm{g}$ & $\leq 13$ & $14-16$ & $\geq 17$ \\
\hline
\end{tabular}


Determination of the minimum inhibitoryconcentration (MIC) in the presenceof glutathione

Sufficient $75 \times 12 \mathrm{~mm}$ sterile capped tubes The effect of exogenous glutathione on the antibacterial activity of levofloxacin was investigated in two clinical bacterial isolates (S. aureus and E-coli) which were provided by Urology department at MenoufiyaUniversityHospital.The determination of the MIC for levofloxacin was performed using the brothmacrodilution test, according to the Clinical and LaboratoryStandards Institute (CLSI, 2016).

Preparation ofantioxidant: antioxidant was freshly prepared before use. Stock solutions $(10 \mathrm{mM})$ of glutathione was prepared in sterile distilled water

Preparation of antibiotic dilution range: Dilution ranges for levofloxacin $(0.03 \mu \mathrm{g} / \mathrm{ml}$ $128 \mu \mathrm{g} / \mathrm{ml}$ ) for levofloxacin - glutathione .

\section{Preparation of inoculum:}

The inocula were adjusted to $10^{5} \mathrm{CFU}$ (equal to $0.5 \mathrm{McF}$ arland standard).

Inoculation were arranged in two rows for each antibiotic to cover the range of antibiotic dilutions chosen in duplicate. One $\mathrm{ml}$ volumes of levofloxacin dilution in broth were transferred to the tubes.

A final inoculum of $10^{5} \mathrm{CFU} / \mathrm{ml}$ was required and therefore suspensions were diluted 1:100 in broth medium for preparing the antibiotic dilutions. One $\mathrm{ml}$ aliquots of test organism to one set of tubes and $1 \mathrm{ml}$ of control organism to the other.Contents of thetubes were mixed thoroughly, incubated for $18-20$ hours at $35^{\circ}$ C

\section{Reading and interpretation:}

the MIC endpoint was read as the lowest concentration of antibiotic that prevented bacterial growth after $18 \mathrm{~h}$ of incubationwas the MIC, both in the presence and absenceof glutathione.

table3. Levofloxacin susceptibility of S. aureus by MIC tube dilution method (CLSI, 2016)

\begin{tabular}{|l|l|l|l|}
\hline Antibiotic & Resistant & Intermediate & Sensitive \\
\hline Levofloxacin & $\geq 4$ & 2 & $\leq 1$ \\
\hline
\end{tabular}

Table 4. Levofloxacin susceptibility of E. coli by MIC tube dilution method (CLSI, 2016)

\begin{tabular}{|l|l|l|l|}
\hline Antibiotic & Resistant & Intermediate & Sensitive \\
\hline Levofloxacin & $\geq 2$ & $0.25-1$ & $\leq 0.12$ \\
\hline
\end{tabular}

\section{RESULTS AND DISCUSSION}

Regarding antibiotic susceptibility of isolated $S$. aureus and E-coli,bothisolates were sensitive to levofloxacin.

In S. aureus, the values of MIC obtained for levofloxacin was $1 \mu \mathrm{g} / \mathrm{ml}$. When the sensitivity to antibiotics was determinedin the presence of glutathione, there were no significantchanges in the MIC(Table 1).

In $E$-coli, the values of MICwas $0.12 \mu \mathrm{g} / \mathrm{ml}$ for levofloxacin.

In thepresence of glutathione, there were no significant changes in the MIC (Table 2). 
Table 5.Effect of addition ofglutathione on the susceptibility of $S$. aureus and $E$-colito levofloxacin

\begin{tabular}{|l|l|l|l||}
\hline MIC $(\mu \mathrm{g} / \mathrm{ml})$ & $\begin{array}{l}\text { S. aureus } \\
\text { MIC }\end{array}$ & $\begin{array}{l}\text { E-coli } \\
\text { MIC } \\
(\mu \mathrm{g} / \mathrm{ml})\end{array}$ & P value \\
\hline Levofloxacin & 1 & 0.12 & \multirow{2}{*}{ P $>0.05$} \\
\hline Levofloxacin and glutathione & 1 & 0.12 & \\
\hline
\end{tabular}

$\mathbf{P}>\mathbf{0 . 0 5}=$ not significant

This study showed that the antibacterial activity of levofloxacin wasnot affected by presence of glutathione as it was previously shown that synthetic quinolone antibioticspromoted the formation of the hydroxyl radical that contributed

to cell death (Kohanski et al., 2007), and it wasproposed that oxidative damage contributes to bactericidalcell death following gyrase poisoning with an oxygendependentdeath pathway appearing to amplify the primaryeffect on gyrase(Dwyer et al., 2007)and Glutathione was chosen because it is a scavenger of ROS, which has been shown to be involved in protecting the celleither directly or indirectly. This might constitute an adaptiveresponse to oxidative damage, which is known toincrease in the presence of the antibiotic (Prinz et al., 1997;Pomposiello\&Demple, 2002).

A previous study conducted on E. coli suggeststhat glutathione modulates the effect of antibiotics (Goswami\&Jawali, 2007). These authors reported a reduction inMIC for ampicillin and penicillin, from 8 to $4 \mathrm{mgmL} 1$ andfrom 64 to $48 \mathrm{mgmL}$ _, respectively.also this result come in line with (Goswami.,et al 2011). as they reported that GSH can act as an importantmodulator of antibiotic susceptibility for bacteria asitaugments the efficacy of $\beta$ lactams suchas penicillin and ampicillin on $\mathrm{E}$. coli cellswhich become more susceptible towards themin presence of GSH(Goswami.,et al 2011).

\section{CONCLUSION}

On the basis of our studies it can be concluded thatantibacterial action of therapeutically relevantantibiotics could be augmentedby the presence of antioxidants like GSH andthese findingsare of immense values for further investigations surrounding the intake ofantioxidants on antibacterial effect of differentantibiotics for treatment of various infections arewarranted in future.

\section{REFERENCES}

Albesa, I.;Becerra,MC.;Battán,PC.;Pa'ez PL (2004) Oxidative stressinvolved in the antibacterial action of different antibiotics.BiochemBiophys Res Commun 317: 605-609.

Becerra,MC.andAlbesa.I.(2002). Oxidative stress induced byciprofloxacin in Staphylococcus aureus. BiochemBiophys ResCommun 297: 1003-1007.

Cexiong, F.; Changgong ,W.; Tong, L.; Tetsuro ,A.; Peiyong, Z.; Junichi, S .; Hong,B. (2009) Elucidation of thioredoxin target Protein networks in mouse.JBacteriol 191: 3403-3406.

Goswami, M.; Mangoli, S.; \&Jawali, N.(2011). Antibiotics andAntioxidants: Friends or Foes During Therapy? BarcNewesltter.Issue NO. 323. 
Goswami, M.;Mangoli,SH.;Jawali, N. (2006) Involvement of reactiveoxygen species in the action of ciprofloxacin against Escherichiacoli. Antimicrob Agents Chemother 50: 949-954.

Kohanski,MA.; De Pristo,MA.; Collins, JJ. (2010) Sublethal antibiotictreatment leads to multidrug resistance via radicalinducedmutagenesis. Mol Cell 37: 311320.

Koneman, EW.; Winn, WJ.; Allen , Janda, W.; Procop, G.; Wood.G, et

al. Koneman's Color Atlas and Textbook of Diagnostic Microbiology. London: Lippincott Williams \&Wikins; 2006. PP.

211-264.

Miller ,P. and Sulavik, MC. (1996) Overlaps and parallels in the egulationof intrinsic multiple-antibiotic resistance in Escherichia coli. MolMicrobiol 21: 441448.
Naeem ,A.; Badshah ,S.; Muska ,M.; Ahmad ,A.; Khan ,KH.(2016) The Current Case of Quinolones: Synthetic Approaches and Antibacterial Activity Molecules, 21, 268; Doi:10.3390/molecules21040268

Oethinger, M.; Podglajen, I.; Kern, WV.; Levy, SB. (1998) overexpression of the marA or soxS regulatory gene in clinicaltopoisomerase mutants of Escherichia coli. Antimicrob Agentschemother 42: 2089-2094.

Pa'ez,PL.; Becerra, MC .;Albesa, I. (2010) Effect of theassociation ofreduced glutathione and ciprofloxacin on theantimicrobial activity in Staphylococcus aureus. FEMSMicrobiolLett 303:101-105.

Wick,LM.andEgli,T. (2004)Molecularcomponents of physiologicalstress responses in Escherichia coli. AdvBiochemEngBiotechnol89: 1-45. 